\title{
MERCADO, HUMANIDADES Y EDUCACIÓN: UN ANÁLISIS DESDE LA ONTOLOGÍA SOCIAL ${ }^{1}$
}

\author{
Rodrigo Alfonso González Fernández \\ Universidad de Chile \\ rodgonfer@gmail.com
}

Professors of the humanities have lost the power to rescue themselves.

Frank Donoghue, The Last Professors

\begin{abstract}
RESUMEN / ABSTRACT
En el marco de los estándares profesionalizantes de la academia, con sus "rankings" y productividad científica, las humanidades subsisten. Una explicación de este fenómeno es que, según la ontología social, las razones para la acción independiente de deseos son piezas clave en la educación. Por ello, dichas razones, que constituyen obligaciones, también serían claves para el desarrollo de las humanidades. Aquí examino de qué forma el individualismo y la competencia tensionan la dinámica entre deseos y obligaciones. Ciertamente, el mercado valora más la satisfacción de deseos que la teorización sobre la intencionalidad colectiva y su producto: la civilización humana.

Palabras Clave: humanidades, educación, mercado, deseos, obligaciones, razones para la acción independiente de deseos.

\section{MARKET, HUMANITIES AND EDUCATION: AN ANALYSIS FROM SOCIAL ONTOLOGY}

Within the framework of the highly professionalized standards of the academy, with its rankings and scientific productivity, humanities subsist. A possible explanationof this phenomenonis that, according to Social Ontology,desire-independent reasons for action are the key in contexts of education, and of humanities. In this paper, I examine how the market forces, which favor individualism and competition, creates tension between desires and obligations. As I argue here, in market contextsactions that satisfy desires are more valued than the theorization about collective intentionality and its product: the human civilization.
\end{abstract}

KEYWORDS: Humanities, education, market, desires, duties, desire-independent reasons for action.

Agradezco la discusión de este trabajo a Jorge Prado, Guido Vallejos y Felipe Morales. Sin su valiosa ayuda este no sería lo que es. 


\section{Introducción}

$\mathbb{R A}$ Cuando Ernesto Sábato (1970) diagnosticó la alienación del ser humano, producto de la cuantificación del mundo post Renacimiento, y especialmente del dominio del capitalismo, muchos consideraron que su análisis carecía de rigor, y que estaba motivado por una actitud emocional en contra de un sistema político-económico. Tal sistema ha privilegiado la eficiencia y la competencia sin medida, afectando el desarrollo no solo de las humanidades, sino de una visión integral y abarcadora del ser humano, que no solo apunte al desarrollo económico, sino a la mantención y fortalecimiento de la intencionalidad colectiva, base de toda la realidad institucional.

Pese a las críticas, el diagnóstico de Sábato ha sido acertado, pues las humanidades actualmente subsisten en el vaivén de las fuerzas de mercado. Disciplinas como la filosofía, la historia, la literatura, la lingüística, entre otras, han sido afectadas por la valoración sin contrapeso de la competencia y la eficiencia. Paradójicamente, frente a la subsistencia de las humanidades, otros diagnósticos culpan a las propias disciplinas humanísticas, pues no han sabido adaptarse al escenario político-económico del capitalismo.

Este trabajo, que está dividido en tres secciones, ofrece un diagnóstico acerca de la relación entre mercado, educación y humanidades, teniendo en consideración la ontología social de John Searle (1995 y 2010). En la primera sección, se proporciona el contexto general de dicha ontología, explicando cómo en contextos de la educación priman las razones para la acción independiente de deseos. Como se sostiene aquí, tales razones son claves para entender por qué las humanidades subsisten en el mercado. En la segunda sección, se describe de qué forma el mercado ejerce excesiva presión sobre los deseos, cuestión que va precisamente en contra del desarrollo de las humanidades. Finalmente, en la tercera y última sección, se elucida cómo la competencia afecta el desarrollo de dichas disciplinas, al tensionar la dinámica entre deseos y obligaciones. El ejercicio de estas, se argumenta, es lo que posibilita navegar en un mar de instituciones. Las humanidades, justamente, favorecen tal navegación, al reconocer y mantener la civilización humana.

\section{Searle y la ontología social: la importancia de las razones para la acción independiente de deseos}

Desde sus inicios, los filósofos tienen una obsesión teórica: explicar y comprender el mundo en su totalidad. Dicha obsesión ha dado lugar a distintos afanes. Primero, los filósofos se obsesionaron con encontrar el principio de todas las cosas. En segundo lugar, se enfocaron en el bien y la justicia. En tercer lugar, se concentraron en proponer las condiciones necesarias y suficientes del conocimiento. Mucho tiempo después, centraron sus investigaciones en el lenguaje, al pensar que el riguroso análisis de este solucionaría problemas filosóficos perennes. Por supuesto, es cuestionable que estas obsesiones hayan sido resueltas parcial o totalmente, incluso en la época contemporánea. 
En esta, John Searle (1990 y 2010) tiene una obsesión distinta: elucidar el surgimiento y mantención de la civilización. Su objetivo es novedoso, al punto de que frisa los estudios de la sociología, aunque entre él y los sociólogos hay mutuo desconocimiento. Sin duda, las explicaciones sociales y psicológicas atañen tanto a las ciencias sociales como a la filosofía (Searle 1995, p. 140 y 2004, p. 22). Mientras ha habido timidez por parte de los filósofos para explicar el surgimiento y mantención de la civilización, los sociólogos han pecado de un celo poco justificable. Pero, explicar tal fenómeno exige una aproximación interdisciplinaria, que incluya a la filosofía y a disciplinas como la sociología y la antropología. De este modo, la obsesión de Searle por elucidar la civilización parece justificada.

En efecto, explicar cómo se pasa de partículas y sistemas de partículas a repúblicas, congresos, fiestas, deportes, etc., no es fácil tarea (Searle 1998, pp. 112113). Sin embargo, las herramientas de Searle son prometedoras. Tener métodos como la teoría de los actos de habla y de la intencionalidad permite comprender qué es, cómo surge y, especialmente, cómo se mantiene la civilización. Ciertamente, esta depende del funcionamiento de la conciencia, de la intencionalidad individual y colectiva, y del lenguaje. De la conciencia, porque los seres humanos son conscientes de lo que les acontece a ellos en su entorno. De la intencionalidad, puesto que los seres humanos son capaces de representar, simbólicamente, paso necesario para la creación de funciones e instituciones. Y del lenguaje, debido a que dichas instituciones necesitan ser declaradas como tales para que existan.

Con base en las teorías del lenguaje, la mente y el surgimiento de la sociedad, uno podría afirmar responsablemente que Searle ha propuesto un sistema filosófico que explica la totalidad del mundo. Como se sabe, los sistemas son cosa rara en la filosofía contemporánea, porque se requiere de varias herramientas teóricas, que expliquen la totalidad de la realidad. No basta con que porciones de la misma resulten elucidadas, como los hechos brutos, que se explican desde un punto de vista científico. Estos, que no son observador-dependientes (e.g. el choque de las placas tectónicas), solo dan cuenta de una parte de lo que hay alrededor de uno. Pero, la ontología exige más, a saber, que toda la realidad sea explicada, independientemente de si hay porciones de ella que son observador-dependientes u observador-independiente. De este modo, el sistema de Searle es integrador, porque explica todo lo que existe alrededor de uno.

Su teoría del surgimiento y mantención de la civilización es analítica, pero a la vez sintética. Es analítica en relación con los problemas ligados al surgimiento de la civilización: por ejemplo, los actos de habla y los estados mentales intencionales. Pero, es sintética también (Searle 1998, p. 6), en el sentido de que vincula mente, lenguaje y sociedad. Hay un nexo entre estos tres hitos metafísicos, al punto de que los estados mentales intencionales son necesarios para los actos de habla, y estos suficientes para la creación de instituciones en la sociedad. No hay instituciones sin lenguaje (Searle 2010, p. 62). No hay, por lo mismo, una contradicción en el método serleano, que emplea el análisis y la síntesis. Ambos métodos son necesarios para mostrar de qué forma todo lo que hay, todo lo que existe pertenece a un solo mundo (Searle 1995, pp. 25-26, y 2010, pp. IX-X). 
Por razones de espacio, caracterizaré brevemente aquí la teoría de Searle del surgimiento y mantención de la civilización. Tal como mencioné arriba, para que ella surja se requieren seres con mente, que sean conscientes y que tengan estados intencionales. Estos últimos son claves, porque permiten, mediante representación, la asignación de funciones agentivas, esto es, de otorgar funciones a objetos independientemente de las propiedades intrínsecas de los mismos. Por ejemplo, un semáforo es de metal y vidrio, pero lo que representa, ser un objeto regulador del tráfico, es dependiente de las mentes de agentes intencionales. Estos creen colectivamente que las luces regulan el paso de peatones y automovilistas. En palabras de Searle, hay funciones de estatus asignadas (Searle 1995, pp. 40-43), que permiten la creación de hechos institucionales, asociados a normas y reglas. Lo anterior se rige por la fórmula es " $\mathrm{X}$ cuenta como $\mathrm{Y}$ en C"; es decir, un aparato de vidrio y metal cuenta como un semáforo, en el contexto de una ciudad.

No obstante, las funciones de estatus son necesarias, pero no suficientes para el surgimiento de la civilización. Hay un elemento adicional, la intencionalidad colectiva, que da lugar a dichas funciones. Aquella es fruto de la asociación y la cooperación, porque permite que se implementen las reglas constitutivas, es decir, las normas para la creación y mantención de las instituciones, las cuales son necesarias y esenciales en la civilización. Esto es, las instituciones se constituyen por el funcionamiento de reglas reconocidas colectivamente, las que permiten la creación y mantención de instituciones en el tiempo. Un ejemplo clásico que pone Searle es el del matrimonio. Este hecho institucional típico de la sociedad civil hace que dos novios se vinculen jurídicamente. Para que pueda existir tal vínculo, se debe contraer matrimonio, pero además debe haber oficiales civiles que declaren a los novios esposos. Las declaraciones son, entonces, fundamentales para la creación de todas las instituciones (Searle 2010, pp. 13, 114).

Hay una serie de poderes negativos y positivos asociados a las instituciones. Por ejemplo, estar casado da derechos y deberes. Entre los primeros cuentan, por ejemplo, el derecho a exclusividad en cuanto a la persona amada. De otra forma, se facilitaría la bigamia. Por otra parte, conlleva deberes como, por ejemplo, el auxilio y socorro mutuos. Si uno de los cónyuges está enfermo, el otro debe socorrerlo para que recupere la salud. En este sentido, los poderes deónticos no solo están íntimamente ligados a las instituciones, a "X cuenta como $\mathrm{Y}$ en $\mathrm{C}$ ", sino además a la intencionalidad colectiva. Más aún, la importancia de los poderes deónticos es crucial para el funcionamiento de la sociedad: uno tiene expectativas en función de ellos. Dichas expectativas se cumplen porque los poderes deónticos funcionan, y porque estos dan sentido a las instituciones de la realidad social.

Las expectativas usualmente se acrecientan con el funcionamiento de las instituciones, y de las consiguientes reglas constitutivas y poderes deónticos. Reglas y poderes van de la mano: no es posible que exista una institución sin reglas constitutivas asociadas a la misma, y que responda a la fórmula "X cuenta como $\mathrm{Y}$ en $\mathrm{C}$ ". El funcionamiento de las instituciones de acuerdo con reglas da lugar a los poderes deónticos, los cuales refuerzan las expectativas y la confianza en las instituciones (Krause y González 2016). Por ejemplo, la policía funciona de acuerdo con reglas constitutivas, pero, además, en función de poderes deónticos. Si un oficial de policía, Luis por ejemplo, tiene derechos y deberes, estos darán lugar a expectativas. Un conductor ebrio detenido por él tendrá 
la expectativa negativa de que será arrestado. No serlo iría contra la policía como institución, es decir, contra las reglas constitutivas de esta y, finalmente, contra los poderes deónticos asociados.

Cuando hay alineamiento de instituciones, reglas constitutivas y poderes deónticos, la civilización llega a su pináculo de desarrollo. Piénsese en una situación en que, en un país con altos índices de corrupción, los poderes deónticos son febles, y dan lugar a toda clase de abusos. Ello lleva al desorden y, peor aún, a la desconfianza y la incertidumbre. Si en un país la policía es corrupta, por ejemplo, es difícil saber qué esperar de ella. En realidad, una certeza es que no actuará como debería, sino como una mafia que operará para su beneficio personal, esto es, para la satisfacción de sus deseos personales. De hecho, los policías corruptos son un ejemplo paradigmático de acción para satisfacer deseos personales, pues no actúan por razones para la acción independiente de deseos. Vuelvo sobre este problema más abajo.

Una cuestión importante de destacar es que la educación es una institución a la que usualmente se asocia el servicio público. De hecho, las instituciones educacionales son ejemplos del nexo entre la intencionalidad colectiva, las funciones de estatus, las instituciones, las reglas constitutivas, y los poderes deónticos. En efecto, desde Sócrates en adelante existe una interesante asociación entre las leyes, la educación, la ciudadanía y las instituciones ligadas a esta. Tómese como ejemplo de lo anterior el pasaje de Lucila Godoy, más conocida como la poetisa Gabriela Mistral: "Hay una alegría del ser sano y la de ser justo, pero hay, sobre todo, la hermosa, la inmensa alegría de servir" (Mistral 2018 , p. 1). Este pasaje de su poema sin duda sintetiza magistralmente la relación entre la educación, la civilización y el servicio.

No es casual que el filósofo, y las humanidades en general, desempeñen un rol central en la educación de sus ciudadanos. La filosofía, la literatura, la historia, la lingüística son disciplinas que están vinculadas a que los ciudadanos de la polis se reconozcan como tales. Dan un sentido de pertenencia e identidad, fortaleciendo el reconocimiento de las instituciones. Tal como el lenguaje es institución de instituciones, la educación es "institución para las instituciones" (González 2015, pp. 5 y ss.), en el sentido de que ella permite navegar en el mundo social. Sin educación no se puede navegar en ese mundo, porque no hay conexión entre las personas y la intencionalidad colectiva asociada a las instituciones, con sus poderes deónticos. En consecuencia, el deber hacia la polis se consolida con el cultivo de las humanidades, al punto de que la filosofía, la historia, la literatura, entre otras, resultan cruciales para consolidar el reconocimiento y mantención de lo ciudadano, de la civilidad.

Los educadores actúan, en jerga de Searle, en aras de razones para la acción independiente de deseos. Es decir, las instituciones educacionales son garantes de que los ciudadanos aprendan las leyes de la polis, pero para que lo hagan, debe haber educadores que sirvan públicamente como tales. Esto, en vista de la ontología social de Searle, explica por qué los educadores actúan en virtud de dichas razones, y no de la satisfacción de sus deseos más inmediatos. Lo anterior explica, además, por qué las razones para la acción independiente de deseos se contraponen a los deseos, que muchas veces tienden a satisfacerse de forma inmediata. 
Hay una contraposición entre la satisfacción de los deseos personales y las razones para la acción independiente de deseos. Un profesor universitario, por ejemplo Juan, tiene que satisfacer deseos personales, pero también puede actuar en virtud de razones para la acción independiente de deseos. Juan puede posponer algunos deseos personales a satisfacerse de manera inmediata, tales como dormir una siesta, ir a un partido de fútbol, hacer un asado, etc., para hacer clases, corregir pruebas, entrevistarse con estudiantes, etc. Nótese que Juan podría satisfacer sus deseos personales más inmediatos, pero no lo hace porque pertenece a una institución educacional, en la que se actúa en virtud de acciones motivadas por razones para la acción independiente de deseos.

Tal como los poderes deónticos son el pegamento de la civilización (Searle 2010, p. 9), las razones para la acción independiente de deseos son los engranajes de ella. En efecto, si todo el mundo actuara en función de la satisfacción de sus deseos personales, la civilización no podría existir. No lo haría porque las instituciones requieren que los poderes deónticos funcionen correctamente, es decir, de que las obligaciones, deberes y derechos que emanan de las instituciones validen las mismas como tales, y que así se posibilite su mantención y reconocimiento. El hecho de que Juan vaya a hacer clases, por ejemplo, mantiene la institución educacional como tal, le da vida y la mantiene. Por lo tanto, sin la implementación de las razones institucionales, no podrían validarse como tales las instituciones, y ello pondría en riesgo la mantención, reconocimiento y continuidad de la civilización.

Ahora bien, no todo sistema político es afín a promover las razones para la acción independiente de deseos. Ciertamente, la civilización requiere un equilibrio entre los deseos personales y tales razones, pues la mantención de dicha civilización depende de estas últimas. Sin embargo, es claro que no todo sistema económico-político propicia el equilibrio antes mencionado. Tal como se analiza en la siguiente sección, el mercado capitalista favorece excesivamente los deseos personales y, por tanto, pone en riesgo la acción en función de las razones independiente de deseos, especialmente en ámbitos de la educación,y ciertamente en los de las humanidades. Tal examen es, precisamente, el objeto de la siguiente sección.

2. Mercado, individualismo y competencia: cómo aquél presiona sobre los deseos

Un slogan de los neoliberales es proteger la libertad, pues esta es la misión del hombre libre. Los neoliberales ponen todo el acento en la libertad individual, negativa, y por ello buscan que el gobierno no se convierta en un Frankenstein; un requisito para esto es que el poder no se concentre en demasía. Los defensores del mercado capitalista incluso ven una estrecha relación entre la libertad económica y la libertad política, como se analizará aquí, pues entienden que la primera es una forma de ejercer la segunda. Y lo es si y solo si hay partícipes en el mercado que no son restringidos y limitados por el gobierno. Dicha restricción se produce, por ejemplo, en una economía centralizada, donde justamente los individuos no pueden emprender individualmente. 
Solo el mercado neoliberal garantizaría que la iniciativa individual se concrete como debe. En consecuencia, para que se pueda ejercer la libertad económica, deberían darse condiciones específicas, las del libre mercado, para que así los agentes de este no sean presa del intervencionismo del gobierno.

Según los neoliberales, el alcance y función de dicho gobierno deben estar entonces limitados. Una forma de que haya demasiada intervención es, como lo pone Milton Friedman, mediante "la preservación de la ley y el orden, el aseguramiento de los contratos privados, y la promoción de los mercados competitivos" (Friedman 1982, p. 11). Justamente, al favorecerse la competencia en el mercado, tanto a nivel de cooperación entre individuos como de empresa privada, se restringiría el poder del gobierno, y con ello se supone que florecería la libertad de expresión, de religión y, especialmente, la de pensamiento. La centralización del poder sería, según los neoliberales al estilo de Friedman, una consecuencia negativa del gigantismo gubernamental, al punto de que la libertad política resultaría necesariamente afectada. Existe, según los mismos neoliberales, un claro vínculo entre el florecimiento de la civilización y la dispersión del poder, garantizada por el libre mercado.

Según reza la doctrina neoliberal, todos los saberes resultan beneficiados si se garantiza la libertad. La ciencia, la arquitectura, la pintura, la literatura, la industria se beneficiarían con la dispersión del poder. De acuerdo con la propuesta de Friedman,

Colón no buscó una nueva ruta a China como respuesta a una orden parlamentaria, aunque fue financiado por un monarca absoluto. Newton y Leibniz; Einstein y Bohr; Shakespeare, Milton y Pasternak; Whitney, McCormick, Edison y Ford; Jane Adams, Florence Nightingale, y Albert Schweitzer; ninguno de ellos abrió las nuevas fronteras en el conocimiento humano y su comprensión, en la literatura, en relación con posibilidades técnicas, o con el sosiego de la miseria humana, como consecuencia de órdenes gubernamentales. Todos sus descubrimientos fueron producto de genialidades individuales, de posturas minoritarias, de un clima social que permitió la variedad y la diversidad (Friedman 1982, p. 11, énfasis mío).

Existiría, entonces, una estrecha relación entre la libertad individual, que promueve la diversidad y la variedad, y el desarrollo de la civilización. Contrariamente a lo que piensa Searle, por ejemplo, no serían las instituciones ni la intencionalidad colectiva los pilares de la civilización humana, sino que estos se constituyen a partir de la acción de los individuos, protagonistas del cambio y el progreso en la historia.

Incluso, el gobierno centralizado no puede emular las posibilidades del genio individual. Estandarizar es una actitud antiprogreso, según el neoliberalismo. Lo es en el sentido de que va contra la variedad y la diversidad ya mencionadas arriba. Por lo mismo, el deseo de igualdad sería anticompetencia, pues los actores del mercado resultarían restringidos en cuanto a sus libertades. Cualquier estandarización, de vestimenta, de alimentación, de vivienda, de escuela, etc. llevaría al estancamiento. Este es causado, una vez más, por la restricción de las libertades e iniciativas individuales. De este modo, de acuerdo con los neoliberales, habría una directa relación entre el desarrollo del individualismo, en el seno del capitalismo, y el incremento de la libertad. 
Más aún, habría una estrecha relación entre libertad y capitalismo. Este último, insisten los neoliberales, es el escenario adecuado para el desarrollo y progreso de la libertad, pues tal como usualmente se sostiene, hay un "rol del capitalismo competitivo que organiza el grueso de la actividad económica mediante el desarrollo de la empresa privada, operando en un mercado libre, como sistema económico de la libertad, y como condición necesaria de la libertad política" (Friedman 1982, p. 12). Los neoliberales siguen, en consecuencia, a aquellos filósofos del siglo XVIII y XIX que enfatizaban la libertad como objetivo primordial, y como entidad social que produce consecuencias positivas en una sociedad.

La doctrina de los antiguos liberales era el laissez faire, al reducir el rol del Estado en los asuntos económicos, lo cual a su vez enfatiza la importancia del individuo, y de toda iniciativa individual. Su otro lema es el intercambio libre entre naciones como una manera de asegurar la paz, por una parte, y de fortalecer la democracia, por otra. Por ello, el desarrollo de esta se ve asociada a la protección de los derechos civiles, especialmente de los individuales. Su lema, nuevamente, es que la libertad económica es parte esencial de la libertad total. Pero, ¿qué es el laissez faire de los antiguos liberales, que ha dado lugar al grueso de la doctrina neoliberal? Dicha expresión es una abreviación de laissez faire, laissez passer. Como lo sintetiza Montenegro:

Como el fenómeno económico es un fenómeno "natural", dicen los fisiócratas, lo lógico es dejar que actúen las leyes "naturales", sin aquella intervención del estado que practicó Colbert. El fisiócrata francés Gournay (1712-1759) acuña la célebre frase: Laissez faire, laissez passer (dejar hacer, dejar pasar). Dejar hacer: cancelar las limitaciones del intervencionismo y abrir campo a la iniciativa individual; dejar pasar: abrir las puertas de las naciones, suprimiendo las barreras aduaneras, de modo que se estimule y active la circulación de la riqueza.

En este punto, y como campeón máximo de laissez faire, laissez passer, se hace presente el liberalismo económico o la teoría de la libertad económica, fundada en la libre iniciativa individual movida por el deseo de lucro; en la libre competencia, reguladora de la producción y de los precios, y en el libre juego de las "leyes económicas naturales” o del mercado (Montenegro 1961, p. 32, énfasis mío).

Es por esto, entonces, que los neoliberales son enfáticos en cuanto a la promoción de la libertad. Según ellos, no es una mera coincidencia que el desarrollo del mercado y el florecimiento de la libertad coincidan. Existe un vínculo necesario entre libertad y capitalismo, al punto de que ambos se retroalimentarían. El mercado, que es la esencia del capitalismo, es un componente de la libertad según ellos y, en consecuencia, habría una íntima relación entre el desarrollo del mercado y la libertad política. Entonces, reza la doctrina de los neoliberales, una sociedad libre se fortalece con los arreglos económicos del mercado capitalista. Por el contrario, una sociedad donde no impera el capitalismo será coercitiva, o bien la libertad estará claramente restringida. Así, suponen los neoliberales, ha sido el desarrollo de la historia de occidente, donde se ha pasado de la centralización del poder, con los monarcas, por ejemplo, a la dispersión del poder, con los mercados, contextos en los que prima la iniciativa individual y la competencia. 
Paradójicamente, tales escenarios habrían reforzado la cooperación, en lugar de la coerción. Aquella se logra cuando las partes involucradas atisban mutuo beneficio cuando cooperan, instancia en la cual las transacciones económicas beneficiosas tienen lugar. El intercambio, en el mercado, se asocia con la coordinación sin coerción, punto que estaría ligado al intercambio económico en el capitalismo competitivo. La competencia es justamente vista como un elemento esencial del mercado, porque no solo es fruto de la libertad, sino que además beneficiaría a los propios agentes del mercado, tanto individuales como empresariales. Más aún, la competencia garantizaría que no haya interferencia en la producción, y que se satisfagan los deseos y necesidades de los actores del mercado, tanto por parte de quienes ofertan como por parte de quienes demandan. Sostienen los neoliberales: el mercado da a quienes demandan lo que quieren, no lo que un grupo piensa que deberían querer. Como lo sintetiza Montenegro:

El primero de los elementos del mecanismo capitalista, según Adam Smith, es el interés egoísta que, traducido en apetito de lucro, mueve la iniciativa privada. Frente a la demanda de los artículos que la sociedad requiere para satisfacer sus necesidades, el individuo busca y crea, en ejercicio de la libertad de empresa, la forma (remunerativa para sí) de satisfacer esa demanda; produce aquellas mercancías que los demás desean adquirir, y las pone a la venta. Produce tanto como puede, incitado por el impulso egoísta de acrecentar sus utilidades. Naturalmente, si el productor fuese uno solo, estaría en condiciones de elevar esas utilidades sin medida, pero aquí interviene el segundo elemento del mecanismo: la competencia. Alucinados por los beneficios que obtiene el primer productor, y en uso de las mismas libertades de empresa, otros individuos siguen sus pasos y producen el mismo artículo $[\ldots]$

El primer productor ve disminuir su clientela (porque ella está comprando productos similares más baratos), se ve obligado a reducir sus precios y utilidades, y de esta manera, en forma "natural", se establece un nivel razonable de precios que beneficia al consumidor impidiendo la especulación abusiva (Montenegro 1961, p. 33).

Ciertamente haré una crítica a los fundamentos neoliberales especialmente en relación con la educación y las humanidades más abajo. Por el momento, resulta más interesante establecer que, pese a la defensa de la libertad que hacen los neoliberales, y especialmente de la competencia, hay una relación entre el mercado y los deseos personales, en que estos adquieren una preeminencia desmedida. De hecho, el mercado no solo hace que los actores de este busquen denodadamente satisfacer sus deseos. Considero que esto aumenta la presión sin medida sobre los mismos. Además, el mercado es capaz de inventar deseos personales, que anteriormente eran inexistentes.

Piénsese, por ejemplo, en una situación hipotética. María desea comprarse vestidos Gucci, porque piensa que son los más atractivos. Pero, María decide no ir al mall, para no tentarse y comprar vestidos Gucci. Sin embargo, los ofertantes que compiten en el mercado se las arreglan para presionar sobre los deseos de los demandantes. Y lo hacen sistemáticamente como una forma de competir con otros actores del mercado. La cadena Arrows, por ejemplo, manda a María un catálogo de vestidos Gucci en su diario. Si bien es posible que María no ceda a la tentación, es claro que hay una presión sobre los deseos personales de ella, que eventualmente dará lugar a la satisfacción de 
los mismos. No solo el mercado favorece una presión sobre los deseos personales, también lo hacen el individualismo y la competencia.

En efecto, el individualismo y la competencia incrementan el ansia de satisfacer los deseos personales, sea de manera inmediata o mediata. Hay una estrecha relación entre competir en el mercado, y triunfar sobre los demás. Piénsese, por ejemplo, en otra situación hipotética, la de Mario. Él es un piloto de avión, y quiere ser el mejor de su compañía aérea Fly Cheap. En este caso, es posible que Mario realice acciones que, si bien pueden ser legales, pueden resultar poco éticas. Puede criticar a espaldas de los otros pilotos colegas el actuar de estos. Mario puede adscribir a la doctrina neoliberal, esto es, de ejercer su libertad individual para competir con los demás. Y puede, hipotéticamente también, no tener escrúpulos si injuria a otros, de una manera reñida con la ética. En consecuencia, el mercado, que supuestamente promueve la libertad, junto con el individualismo y la competencia, pueden presionar excesivamente sobre los deseos personales, al punto de que la satisfacción de estos resulte poco ética. Pero, es especialmente en la educación donde hay consecuencias nocivas cuando el mercado domina.

Tal como he señalado arriba, es el afán socrático de ser educado según las leyes lo que promueve más y mejor el comportamiento ético de los ciudadanos. Con esto se privilegia el sentido genuino que tienen las instituciones, a saber, que respondan a la intencionalidad colectiva, en donde lo público resulta favorecido. En consecuencia, y a diferencia de lo que piensan los neoliberales, hay una estrecha relación entre el comportamiento ético y el reconocimiento y mantención de las instituciones.

En términos similares a lo que he desarrollado en la última parte de esta sección, Ruiz caracteriza, en vista de la modernidad, la preeminencia del Estado en la educación de la siguiente manera:

Si el principio de la república es la virtud política, es decir, la preeminencia constante del interés general por sobre el interés privado, o del bien público sobre el privado, esto quiere decir que la educación es fundamental porque esa preeminencia-como lo sostiene Montesquieu- no es natural, y todo depende en la república democrática de una ciudadanía activa y comprometida con la defensa de este interés general. Una tarea central de la república es, pues, la de formar al ciudadano y esa tarea es la tarea de la educación (Ruiz 2012, p. 13, énfasis mío).

Hay, además del sentido republicano que señala Ruiz², el cual proviene de la Revolución francesa, una necesidad política, ya enfatizada por educacionistas como Valentín Letelier: la de lograr el autogobierno, uno en que la educación no sea vista como un bien económico, ni como una mercadería. En efecto, solo en una educación pública hay,

2 Véase también Ruiz (2010), en donde hay ensayos con descripciones acabadas de la relación entre lo público y la ciudadanía, especialmente desde una perspectiva histórico-política. Aquí, como se ha apreciado, adopto un análisis más bien metafísico, propio de la ontología social de Searle. 
como argumento (González, próximo), un círculo virtuoso entre dicha educación y el desarrollo de instituciones, en el marco de la realidad social serleana. Por ello, coincido con Ruiz en que la educación no debe responder a la lógica de las preferencias, del ejercicio de la libertad al estilo neoliberal, sino de las necesidades de una sociedad. Dichas necesidades tienen que establecerse, a mi juicio, en el contexto de la intencionalidad colectiva, que es, justamente, el fundamento ontológico de las instituciones. Por lo mismo, la promoción de los estudiantes, en una formación abarcadora, que busque una comprensión de sí y del mundo (Ruiz 2012, p. 17), es aquello que debe buscar la educación pública genuina.

Tales ideas son compatibles con una crítica al neoliberalismo, especialmente en cuanto a su visión abstracta de la libertad y del ser humano como individuo aislado de otros, y en competencia (ver, por ejemplo, Letelier 1895, p. 23, en Ruiz 2012). Más aún, ello adelanta por qué las humanidades, que justamente llevan al conocimiento socrático, de sí mismo, de las leyes y de la civilización humana, son claramente afectadas en el contexto de la educación de mercado, que favorece la eficiencia y la competencia. Ambas sobrevaloran los deseos, que explican la demanda en el mercado, y que tienden a menoscabar las obligaciones y compromisos, que fundamentan la existencia de las instituciones emanadas de la intencionalidad colectiva. En la siguiente sección examino de qué manera el mercado lleva a una tensión sin solución para la educación, pero especialmente para el desarrollo de disciplinas humanísticas cuya valoración es inherente al conocimiento de lo humano, y ciertamente de la civilización.

\section{Deseos versus razones para la acción independiente de deseos: una tensión sin solución en el mercado}

Tal como he señalado hasta aquí, no siempre el ejercicio de la libertad total, al estilo del laissez faire, resulta beneficioso. Un claro indicio de que la doctrina neoliberal se fundamenta en un concepto demasiado abstracto de libertad y, entonces, artificial, es lo que sucede con la publicación de obras literarias, especialmente en el área de las humanidades. El neoliberal sostiene que el editor de tales libros no debe publicar aquellos con los cuales está de acuerdo, sino con los que obtendrá un beneficio económico. Es decir, debe satisfacer sus deseos de lucrar. Pero, eso resta fuerza a la publicación en disciplinas humanísticas que no se automercadean [self-marketing]. Por ejemplo, la filosofía, que no es rentable en el mercado capitalista, aunque necesaria en la sociedad, queda precisamente relegada, porque no renta económicamente como debiera.

Sin embargo, el neoliberal se defendería de críticas como esta, asignando un papel específico a la educación en relación con la libertad. Y ciertamente al rol que debe jugar el gobierno a propósito de la educación de los ciudadanos. Su aproximación es diferente de la de Searle, y a la que apoyo aquí: la educación es necesaria para insertar al ser humano en un mar de instituciones. En cambio, según el neoliberal al estilo de Friedman, la educación solo debe responder a la tesis de la dispersión del poder. Como este último argumenta: 
En términos de los efectos, descentralizar la educación escolar dará un abanico de opciones a los padres. Si, como en el presente, los padres pueden mandar a sus hijos a escuelas públicas sin pagar, muy pocos los mandarán a otras, a no ser que sean subsidiadas $[\ldots]$

En general, los padres pueden mandar a sus hijos a escuelas privadas, a un gran costo. Para el resto, pueden expresar sus puntos de vista a través de engorrosos medios políticos $[\ldots]$

La empresa competitiva será mucho más eficiente para satisfacer la demanda de los consumidores en vez de hacerlo en empresas nacionalizadas o de empresas que sirvan a otros propósitos (Friedman 1982, p. 79).

Si la educación es, como argumento, un medio para navegar en un mar de instituciones, la tesis de Friedman resulta claramente cuestionable. Lo es porque no contempla varios puntos en relación con la finalidad de la educación. Entre ellos destaco los siguientes tres puntos:

1. La educación forma ciudadanos de acuerdo con las leyes.

2. La educación, si bien puede ser compatible con la libertad, debe ser emancipadora de todos, no de unos pocos.

3. La educación, especialmente la pública, es integradora de clases, de culturas, en el sentido preciso de que da oportunidades para navegar en ese mar de instituciones.

De hecho, una cuestión que los neoliberales pasan por alto es que en las instituciones educacionales aquellos que dedican esfuerzos a educar actúan postergando sus deseos primarios, y en línea con razones para la acción que son justamente independientes de dichos deseos.

Para ponerlo de manera simple, muchos filósofos creen que las razones son siempre fundamentadas en deseos. Así, toda la racionalidad sería motivada por deseos (Searle 2010, p. 127). Las acciones que se explican por deseos serían motivadas por haber medios para alcanzar un fin (e.g. alguien va al dentista para que le obture una carie, porque ello es un medio para alcanzar un fin: preservar la buena dentadura). De esta manera, tener buena dentadura sería un deseo primario para satisfacer un deseo secundario, y así el último deseo dependería del primero. A diferencia de las acciones que se ejecutan en vista de deseos dependiente de deseos, también hay razones para la acción independiente de deseos. Entre estas últimas justamente figuran el cumplimiento de obligaciones, derechos y similares. Lo que argumento aquí es que la educación es un ejemplo paradigmático de fomentar acciones basadas en razones independiente de deseos, y ello, más abajo analizo, lleva a una tensión en el mercado.

Searle, justamente, enfatiza la cuestión de las razones para la acción independiente de deseos de la siguiente manera: 
Considere mi obligación de dar la clase mañana. Tengo una obligación de hacerlo, si quiero o no. Y tengo varias creencias acerca de los medios para dar la clase mañana. Por ejemplo, puedo manejar al campus y entrar al hall para dar la clase. Hay otras cosas que puedo hacer para preparar la clase. Pero aquí lo interesante es que la obligación para dar clases es independiente de mis deseos. Bueno, ¿qué significa exactamente esto? Significa que tengo una razón para hacerlo que es independiente de lo que sienta en ese momento. Incluso si no tengo ganas de dar la clase en una ocasión particular, o si no me gustaría hacerlo, si reconozco que tengo una obligación, entonces tengo conocimiento de que tengo una razón para hacerlo que es independiente de mis deseos. Mi obligación es un motivador y mi reconocimiento de la obligación es un reconocimiento de la razón para la acción independiente de deseos (Searle 2010, p. 128, énfasis mío).

Todo lo anterior implica, entonces, que en el contexto de la realidad institucional hay obligaciones, y ello implica, además, que algunos deseos deben ser pospuestos en vista de dichas obligaciones. Por ejemplo, Searle podría tener ganas de dormir una siesta a la hora de dar la clase, de leer un libro, de escribir historietas o de ver una película. "[...] Todos estos deseos quedan pospuestos en la medida en que existe una obligación de dar la clase, y que tal razón es motivadora de su acción en un contexto institucional educacional" (Searle 2010, p. 128). En efecto, postergar deseos en aras de razones para la acción independiente de deseos va en línea con los poderes deónticos asociados, por ejemplo, a la institución universidad. En efecto, un profesor, tiene la obligación cuasi kantiana de dar clases (González 2017), en tanto es una obligación institucionalmente motivada. Por tanto, los poderes deónticos, ligados a las instituciones educacionales, dan lugar a razones para la acción independiente de deseos, y que postergan estos últimos.

Ahora bien, innegablemente se produce una tensión cuando los educadores actúan en el marco del mercado, del individualismo y, especialmente, de la competencia. Dado que el libre mercado se basa en la satisfacción de deseos, sean primarios o secundarios, se tenderá primordialmente a la satisfacción egoísta de ambos, y así resultará obvio que habrá tensión entre estos y las razones para la acción independiente de deseos. El egoísmo hará que estos adquieran preeminencia, y que las obligaciones, ligadas a las razones para la acción independiente de deseos, puedan resultar postergadas. "[...] Es obvio, en consecuencia, que el contexto del mercado produce un efecto nocivo no solo en la educación, sino además en las disciplinas que están asociadas con el reconocimiento y análisis del producto final la intencionalidad colectiva: la civilización humana" (Searle 2010, p. 127-128).

Hay una problemática que me gustaría destacar, a propósito del argumento que planteo. El libre mercado, con el egoísmo y la libre competencia, tiende a reversar la lógica de Searle, de las instituciones, poderes deónticos y razones para la acción independiente de deseos. Piénsese en otra situación hipotética: la de José, quien ejerce labores docentes universitarias en el área de las humanidades. De acuerdo con la teoría de Searle, José debería posponer sus deseos para así responder a razones para la acción independiente de deseos. Pero, José se encuentra en un dilema, producto de la tensión entre el mercado y dichas razones. Supóngase lo siguiente: a él se le ha condicionado 
su contrato al estilo tenure track ${ }^{3}$ a que tenga 10 publicaciones ISI (Arts and Humanities Citation Index de la Web of Science). Casi al límite del plazo final tiene solamente 6 publicaciones en ese índice, por lo que dedica gran parte de su esfuerzo a lograr satisfacer el requerimiento que se le ha impuesto.

Es claro que la competencia puede atentar contra las razones para la acción independiente de deseos. Indudablemente, en una situación como la de José, no solo deberá haber un esfuerzo por satisfacer ese requisito, sino que además se deberá hacer eficientemente, de modo que otros no puedan competir con él. Por ejemplo, deberá hacer todo lo que esté a su alcance, postergando no solo otros deseos, primarios y secundarios, sino también algunas de las obligaciones propias de ejercer una carrera docente universitaria. Por ejemplo, es posible que José descuide a sus estudiantes, que no quiera ejercer labores administrativas institucionales o que no quiera dirigir investigaciones de tesis. De esta manera, el mercado, tal como ha ejercido influencia sobre la producción de conocimiento hasta ahora, puede atentar contra las razones para la acción independiente de deseos. Pero, ¿por qué el área de las humanidades resultaría particularmente afectada por el mercado, el individualismo y la competencia?

Las disciplinas humanísticas son afectadas por el mercado de la educación. Ciertamente, la cuestión de la eficiencia no es propia de las disciplinas humanísticas, las cuales florecen y maduran en ámbitos donde se privilegia la reflexión crítica, no la satisfacción de deseos. En efecto, las prácticas corporativas, que actualmente ejercen presión sobre las humanidades, son nocivas para el desarrollo de estas, en la medida en que no responden adecuadamente a afanes egoístas. Pese a que las visiones respecto de este punto son múltiples, quisiera destacar el análisis de Frank Donoghue, quien sostiene lo siguiente en relación con la dinámica que se da en las prácticas corporativas, propias de los negocios, aplicadas a las humanidades. Dichas prácticas privilegian la eficiencia y, en esa medida, pueden llegar a promover una vida anti-intelectual. Sus palabras exactas son las siguientes:

Esperaríamos que los desacuerdos de enfocarse en el dinero y asumiríamos que los capitalistas del siglo XX se quejasen de que las universidades no son eficientes. Lo hicieron, pero estas quejas no explican la intensidad, que bordea la sobreexcitación de sus críticas. En vez de eso, los capitalistas norteamericanos de comienzos del siglo XX fueron motivados por un anti-intelectualismo éticamente basado, que trascendía los intereses financieros más fundamentales. Su desconfianza en los ideales de la investigación intelectual por sí misma los llevó a insistir que si las universidades debían preservarse del todo, deberían operar sobre la base de principios distintos a aquellos que gobiernan las humanidades $[\ldots]$

Andrew Carnegie, el multimillonario pobremente educado, fue tal vez el más temprano y ciertamente el más fiero crítico de la educación de las humanidades, y de su curriculum:

3 Es un contrato en que al profesor universitario se le condiciona su permanencia a subir de jerarquía. 
[...] Me regocija saber que su tiempo no se perderá en el cultivo de lenguas muertas, sino que será empleado en taquigrafía y mecanografía... y que Uds. serán adiestrados en cuestiones relacionadas con vivir la vida y ganársela.

Luego de esta ráfaga de metáforas, Carnegie concluye que "la educación universitaria que existe hoy es fatal" para el dominio de los negocios, y contrasta con fuerza a esos estudiantes educados, "adaptados para vivir en otro planeta" con el "futuro capitán de la industria...involucrado en la educación de la experiencia, que adquiere su conocimiento para triunfos futuros" (Donoghue 2008, p. 3, énfasis mío).

Para el típico defensor del mercado, la educación debe ser un instrumento para ganarse la vida, para competir. Esto, que explica la postergación de las humanidades en el mercado, debe acontecer de acuerdo con los principios que rigen la vida de los negocios. Las humanidades, justamente, son un estorbo, una pérdida de tiempo, una inversión estéril, porque no rinde frutos en dicho contexto mercantilista. Ya en los albores del siglo XX, los defensores del mercado en la educación hablan, como Donoghue argumenta, de factorías de la educación para que los estudiantes se transformen en productos. Capitalistas como Carnegie aseguran, por lo mismo, que si el dinero, pilar de la libertad económica, no es todo, es "al menos el setenta y cinco por ciento de todo" (Donoghue 2008, p. 6). En consecuencia, hay una tensión irreconciliable entre los valores del mercado, y la educación basada en disciplinas humanísticas que reconocen y elucidan las instituciones de la civilización.

El avance y concreción de los valores de la educación no ha tenido límites, y ello ciertamente ha afectado el cultivo de las humanidades. Como se ha argumentado más arriba, uno de los valores que defiende el capitalismo es la libertad individual, base para competir. La competencia es vista por el capitalista como necesaria, incluso en el ámbito de las humanidades, lo cual debe dar lugar a la erudición estandarizada, en un contexto en el cual se privilegie al experto individual. No es casual, entonces, que se compare a una institución como la universidad con un negocio, donde debe haber expertos que vendan su trabajo en función del dinero, del tiempo-trabajo y, sobre todo, de un valor como la eficiencia. Por lo mismo, en el mercado de la educación, la del mercadeo, se valora lo práctico, lo útil, y la universidad es vista entonces como una tienda por departamentos, esto es, como un lugar en que hay eruditos y expertos que deben vender su trabajo, en función de la dinámica de oferta y demanda.

Las humanidades, entonces, deben "operar" en función del progreso, en el mercado. No deben operar en función de la contemplación, condición necesaria para la reflexión en humanidades, sino del negocio. Como la competencia debe primar en la educación de mercado, y ciertamente en las humanidades, los académicos se consideran parte de un sistema en que debe primar el mérito en el contexto de la competencia. De hecho, es sintomático que los académicos de las universidades no se agrupen, por ejemplo, en sindicatos. En el sistema de la universidad corporativa, su autoimagen es la de profesores que deben triunfar, haciendo mérito individual, y ello lleva entonces a competir con otros profesores. Se desarraiga, en consecuencia, uno de los pilares institucionales de la universidad, su origen en la intencionalidad colectiva serleana, como una instancia clave para aprender a navegar en un mar de instituciones. 
Una cuestión crucial, propia del panorama de las humanidades sometidas a la tensión del mercado, es como lo pone Donoghue de una manera pesimista, que los humanistas no han sabido responder al avance de la universidad corporativa:

Los humanistas nunca han sabido responder adecuadamente a dos objeciones de los industriales del siglo XX. El primero, tiene que ver con los contenidos del curriculum. Figuras como Carnegie, Crane y Birdseye preguntaron ¿qué utilidad tienen los estudios académicos tradicionales? [...]

La segunda objeción corporativa a los humanistas ha fallado en ser estudiada cuidadosamente [...] Los críticos corporativos del siglo XX de la educación superior han enfatizado que la universidad debe entrenar a la gente en temas relacionados con los negocios, y que la universidad debe funcionar como un negocio. Los escritos de Birdseye, Taylor y Cooke implican directamente que los profesores universitarios no son diferentes de otros trabajadores, y que deben ser administrados de esa manera (Donoghue 2008, p. 21, énfasis mío).

Concluye este autor que los intelectuales en las universidades han perdido la conciencia de qué significa estar en la academia, algo que indudablemente ocurre hoy. Justamente, el análisis que he efectuado hasta aquí es complementario a la tesis de Donoghue, en la medida en que analiza críticamente:

1. Por qué los intelectuales y académicos están presionados por razones para la acción dependiente de deseos.

2. De qué forma la educación de mercado, y también de mercadeo, involucra una tensión irreconciliable con las humanidades, ajenas al negocio.

En vista del análisis efectuado aquí, resulta evidente entonces por qué las humanidades están postradas en el mercado. A pesar de ser disciplinas que favorecen navegar en una mar de instituciones, y de hacer que las personas se reconozcan a sí mismas como partes de la civilización humana, son ajenas a valores como la competencia y la eficiencia. Justamente, en la ontología social, los poderes deónticos asociados a las reglas constitutivas de las instituciones resultan desfavorecidos por el individualismo y la competencia, bases del mercado. En efecto, dichos poderes, y las obligaciones relacionadas con la educación y las humanidades, resultan socavadas por las fuerzas del mercado. Estas ven en las humanidades un cultivo de saberes no eficientes, ajenos a los negocios, y a lo que se denomina "la vida diaria". Como sostengo aquí, el negocio es, precisamente, el medio para satisfacer deseos. Pero en la educación, y especialmente en las humanidades, la dinámica de investigación y producción de conocimiento se rige por una racionalidad ajena a deseos.

\section{Conclusión}

Las fuerzas del mercado tensionan la lógica descrita por Searle en el ámbito de la educación, pero especialmente en las disciplinas humanísticas. Lo hacen porque, a 
diferencia de la filosofía, la historia, la literatura, la lingüística, etc., en el mercado rige la eficiencia, y en esta medida, se privilegia la satisfacción de deseos egoístas. Hay, en verdad, una lógica inédita en las humanidades, en el sentido de que no se ha enfatizado suficientemente de qué forma el mercado las afecta. Por una parte, lo hace por el egoísmo que privilegia, y que lleva, por ejemplo, a la universidad corporativa. Por otra, por la competencia, que socava las bases de los poderes deónticos, y especialmente de las razones para la acción independiente de deseos. Tal como he destacado aquí, dichas razones explican las obligaciones, deberes y compromisos asumidos en vista de la intencionalidad colectiva, y que son condición suficiente para desenvolverse en el mundo de la educación.

En este trabajo he explorado la tensión entre deseos y obligaciones, mostrando que las humanidades solo pueden subsistir en el contexto del mercado. En particular, he analizado cómo, en el ámbito de la educación, las acciones se basan en razones para la acción independiente de deseos. Dichas razones son justamente lo que motiva no solo el servicio a la comunidad, sino además la navegación en un mar de instituciones, lo cual implica su reconocimiento y mantención en la civilización humana. En síntesis, he argumentado que el mercado, el cual privilegia la eficiencia por sobre la producción de conocimiento sin interés, afecta toda forma de teorización en humanidades. En efecto, al afectar a las disciplinas humanísticas, se llega a una consecuencia no esperada, a saber, el no reconocimiento y elucidación del producto final de la intencionalidad colectiva serleana: la civilización humana.

\section{Referencias bibliográficas}

Donoghue, Frank (2008), The Last Professors: The Corporate University and the Fate of the Humanities. New York: Fordham University Press.

Friedman, Milton (1982), Capitalism and Freedom. Chicago: The University of Chicago Press.

González, Rodrigo (2015), “Educación pública chilena: Un análisis desde la Ontología Social de John Searle", Revista de Estudios Pedagógicos Universidad Austral. Vol. 41, 2: 359-372.

(2017), "Razón crítica kantiana. Un imperativo teórico fundado en la autonomía”, en D. Alegría y P. Órdenes, eds., Kant y los retos prácticomorales de la actualidad. Madrid: Tecnos; pp. 108-120.

Krause, María Soledad y Rodrigo González (2016), "La confianza en la construcción de la realidad social", Revista de Filosofia Universidad Complutense de Madrid. Vol. 41, 1: 33-53.

Letelier, Valentín (1895), “Los pobres”, en diario La Ley, Santiago, $1^{\circ}$ enero de 1896.

Mistral, Gabriela (2018), “El Placer de Servir”. Último acceso en marzo de 2018, http://occidente.co/el-placer-de-servir-6/

Montenegro, Walter (1961), Introducción a las doctrinas político-económicas. México, D.F.: FCE. 
Ruiz S., Carlos (2010), De la República al Mercado: Ideas educacionales y política en Chile. Santiago de Chile: LOM.

(2012), "La República, el Estado y el Mercado en la Educación”. Revista de Filosofía. Volumen 68: 11 - 28.

Sábato, Ernesto (1970), Hombres y Engranajes. Buenos Aires: Emecé editores.

Searle, John (1995), La Construcción de la Realidad Social. Barcelona: Paidós. (1998), Mind, Language and Society. New York: Basic Books.

(2004), Mind: A Brief Introduction. Oxford: OUP.

(2010), Making the Social World: The Structure of Human Civilization. Oxford: OUP. 